\title{
Phosphogypsum Processing for Rare Earths Recovery-A Review
}

\author{
Xiaosheng Yang1, Dandara Salvador'1, Hannu Tapani Makkonen', Lassi Pakkanen² \\ ${ }^{1}$ GTK Mintec, Geological Survey of Finland, Outokumpu, Finland \\ ${ }^{2}$ Geological Survey of Finland, Espoo, Finland \\ Email: jason.yang@gtk.fi, dandara.salvador@gtk.fi, hannu.t.makkonen@gtk.fi, lassi.pakkanen@gtk.fi
}

How to cite this paper: Yang, X.S., Salvador, D., Makkonen, H.T. and Pakkanen, L. (2019) Phosphogypsum Processing for Rare Earths Recovery-A Review. Natural Resources, 10, 325-336. https://doi.org/10.4236/nr.2019.109021

Received: May 20, 2019

Accepted: September 8, 2019

Published: September 11, 2019

Copyright (c) 2019 by author(s) and Scientific Research Publishing Inc. This work is licensed under the Creative Commons Attribution International License (CC BY 4.0).

http://creativecommons.org/licenses/by/4.0/

cc) (i) Open Access

\begin{abstract}
As a by-product from the phosphate fertilizer industry Phosphogypsum (PG) was considered a potentially valuable source of the rare earth elements (REEs). Because of trace concentration of REEs in the PG (normally $<0.1 \% \mathrm{wt}$ ) and also their tiny and complex occurrence phases the recovery process would be highly challenging in both technology and economy. The studies on occurrences of REEs, REE recovery by physical methods and leaching using different lixiviants such as inorganic acids, $\mathrm{H}_{2} \mathrm{SO}_{4}, \mathrm{HCl}$ and $\mathrm{HNO}_{3}$, and organic chemicals, the effects of mechanical treatment of PG by microwaving and grinding on leaching efficiency of REEs, and resin-in-leach process were reviewed in the paper.
\end{abstract}

\section{Keywords}

Phosphogypsum, Rare Earth Elements, Phases of Rare Earth Elements, Acid Leaching

\section{Introduction}

As a by-product from the phosphate fertilizer industry phosphogypsum (PG) mainly contains gypsum $\left(\mathrm{CaSO}_{4} \cdot 2 \mathrm{H}_{2} \mathrm{O}\right)$ and also notable levels of impurities originating from the source phosphate rock such as $\mathrm{Sr}, \mathrm{Ba}, \mathrm{Si}, \mathrm{P}, \mathrm{Fe}, \mathrm{Al}, \mathrm{Ti}, \mathrm{U}$, and Th etc., as well as rare earth elements (REEs). PG had been found to be potential in agricultural use (three of the essential elements for plants growth, calcium, sulfur and phosphorus), uses as construction materials (e.g. utilizing PG in cement) and as a chemical raw material such as for recovery of sulfur and subsequent sulfuric acid manufacturing, as well as for production of ammonium sulfate [1]. Meanwhile, these trace elements are considered one of the main environmental concerns associated with PG [2]. 
Rare earth elements (REEs) comprising 15 lanthanides plus $\mathrm{Y}$ and Sc were normally contained in the phosphate rocks in various contents of 0.03 to 1.0 wt\% [3] [4]. PG was considered a potentially valuable source of REEs. For the phosphate rocks with different REE grades it was concluded that most $(60 \%$ $70 \%$ ) of the initial REE contents were incorporated to the PG during the wetprocess of phosphoric acid [5]-[11]. As much as 5 tonnes of PG were produced for each tonne of $\mathrm{P}_{2} \mathrm{O}_{5}$ affected by the composition of the phosphate rock [12]. It was estimated that 170 or even 280 million tonnes of PG were globally produced annually. If assume the average content of REEs in the PG being $500 \mathrm{mg} / \mathrm{kg}$ the potential source of REEs from the PG would be annually 85,000 - 140,000 tonnes. It was estimated that in Florida alone, approximately 30,000 tonnes of REEs were discarded with various phosphate mining wastes annually [1]. In South Africa up to $85 \%$ of REEs were precipitated with PG during the acidulation of Phalaborwa phosphorite with sulphuric acid [13]. Similarly, in Poland 70\% of REEs were found in PG during dihydrate process for the Kola phosphorite [14]. In Finland, the Siilinjärvi mine annually produced 1.3 million tonnes of apatite concentrate and meanwhile, around 1.5 million tonnes of PG were produced from the processing of the apatite concentrate. It was estimated that the majority $(60 \%-80 \%)$ of REEs from the apatite concentrate, that is, over 2000 tonnes of REEs annually, were deposited into the waste in the mine.

However, processing PG for the extraction of REEs and other valuable elements had not been industrially realized. Trace concentration of REEs in the PG (normally $<0.1 \mathrm{wt} \%$ ) and also their tiny and complex occurrence phases could cause the extraction process of REEs from PG to be highly challenging in both technology and economy. In this paper, the studies and investigations on PG processing for REE extraction were reviewed and the potential feasibilities of approaches in economy are discussed.

\section{Occurrences of REEs in PG}

The occurrence phases of REEs in PG were concerned in many studies but conclusions were disputable [6] [9] [15]-[20]. Generally, according to these studies REEs occurred as sulphates, carbonates, fluorides and phosphates and also being adsorbed as REEs ${ }^{3+}$ ions. Recently, REE occurrences in PG were studied [21] with a European sample. Chemical analysis by ICP-MS showed that all the REEs except Pm exist and La, Ce, Pr, Nd, Sm, Eu, Gd, Dy and Y were found with relatively high concentrations. The content of total REEs (TREE) was around 2200 $\mathrm{mg} / \mathrm{kg}(0.2 \mathrm{wt} \%)$. Gypsum as the dominating mineral in the PG was detected by the mineral liberation analysis (MLA) and the electron microprobe analyses (EPMA) to be the major REE-bearing phase and carry most (over 72\%) of REEs. Other REE-bearing phases are monazite and apatite etc.

\section{Recovery of REEs from PG by Physical Methods}

Because of low grades of REEs an economical approach for recovery of REEs 
from PG should be firstly treated by physical methods to upgrade the REEs in the material prior to further processing such as leaching. The feasibility studies of enrichment of REE-bearing phases by physical methods such as hydrodynamic sedimentation, flotation and high gradient magnetic separation (HGMS) were conducted [22]. Ce and La, two REEs with high concentrations in the PG sample, had the grades of $0.1 \mathrm{wt} \%$ and $0.03 \mathrm{wt} \%$, respectively. Monazite as the major REE-bering mineral in the material had the grade of $0.04 \mathrm{wt} \%$. Figure 1 shows the grades and recoveries of $\mathrm{Ce}$ and $\mathrm{La}$, and monazite in the beneficiation concentrates for four tests. The testing conditions were: in Test 1 PG was treated by HGMS; in Test 2 PG was treated by flotation and HGMS; in Test 3 PG was ground first and then treated by flotation and HGMS; and in Test 4 PG was deslimed by hydrodynamic sedimentation and then treated by HGMS. It is seen that the REEs (Ce and La) and the mineral monazite in the PG could effectively enriched, that is, the grades of La and Ce can reach $2.5 \mathrm{wt} \%$ and $4.8 \mathrm{wt} \%$, respectively, and the grade of monazite can reach $10.5 \mathrm{wt} \%$ (Figure $1(\mathrm{a})$ ). However, elemental and mineral recoveries shown from Figure $1(\mathrm{~b})$ were very different. The recoveries of the REEs were extremely low, only $4.9 \%-8.5 \%$ for La and $3.3 \%-5.8 \%$ for Ce, and the recovery of monazite was quite high reaching $22 \%$ $55 \%$.

The results shown in Figure 1 approved that the REE-bearing minerals in the PG such as monazite could be enriched by physical methods with a quite high recovery but the recovery REEs such as La and Ce in this study was very low. The main reason was that most (over 72\%) of REEs in the PG are carried by gypsum which was not able to be efficiently enriched by physical methods. The lost REEs in the beneficiation process were mainly those carried by gypsum.

\section{Acid Leaching of REEs from PG}

Recovery of REEs from PG by acid leaching has been investigated extensively. Leaching with acids $\mathrm{HCl}, \mathrm{HNO}_{3}$ and $\mathrm{H}_{2} \mathrm{SO}_{4}$ was compared for the PG from Redwater Fertilizer plant in Alberta, Canada [19]. The XRD analysis revealed that the three main solid phases were gypsum $\left(\mathrm{CaSO}_{4} \cdot 2 \mathrm{H}_{2} \mathrm{O}\right) 84 \mathrm{wt} \%$, anhydrite $\left(\mathrm{CaSO}_{4}\right) 8 \mathrm{wt} \%$, and calcium phyllo-tetraphosphate $\left(\mathrm{Ca}\left(\mathrm{P}_{4} \mathrm{O}_{11}\right)\right) 8 \mathrm{wt} \%$. Y, La, Ce, $\mathrm{Nd}, \mathrm{Sm}$, and $\mathrm{Pr}$ were detected in both elemental as well as oxide form by TOF-SIMS (time-of-flight secondary ion mass spectrometry). The results showed that the leaching efficiency of REEs using $\mathrm{H}_{2} \mathrm{SO}_{4}$ was significantly lower than that of $\mathrm{HCl}$ and $\mathrm{HNO}_{3}$ and the reason is that solubility of gypsum in $\mathrm{H}_{2} \mathrm{SO}_{4}$ is much lower than in $\mathrm{HCl}$. It was observed that at $80^{\circ} \mathrm{C}$ the solubility of gypsum in $\mathrm{H}_{2} \mathrm{SO}_{4}$ was about 4 times lower than that in $\mathrm{HCl}(0.075 \mathrm{~mol} / \mathrm{l}$ vs. $0.3 \mathrm{~mol} / \mathrm{l}$, respectively) [23]. Similar results with $\mathrm{HCl}$ and $\mathrm{HNO}_{3}$ were obtained that the average leaching efficiency (only considering REEs with high concentrations in the PG sample: Ce, La, Nd, Sm, and Y) after 20 min was 57\% for the case of $\mathrm{HNO}_{3}$ and $51 \%$ for the case of $\mathrm{HCl}$, both at the conditions of $1.5 \mathrm{~mol} / \mathrm{l}$ concentration, $80^{\circ} \mathrm{C}$, solid to liquid (S/L) ratio of $1 / 8$, and $500 \mathrm{rpm}$ agitation. The 


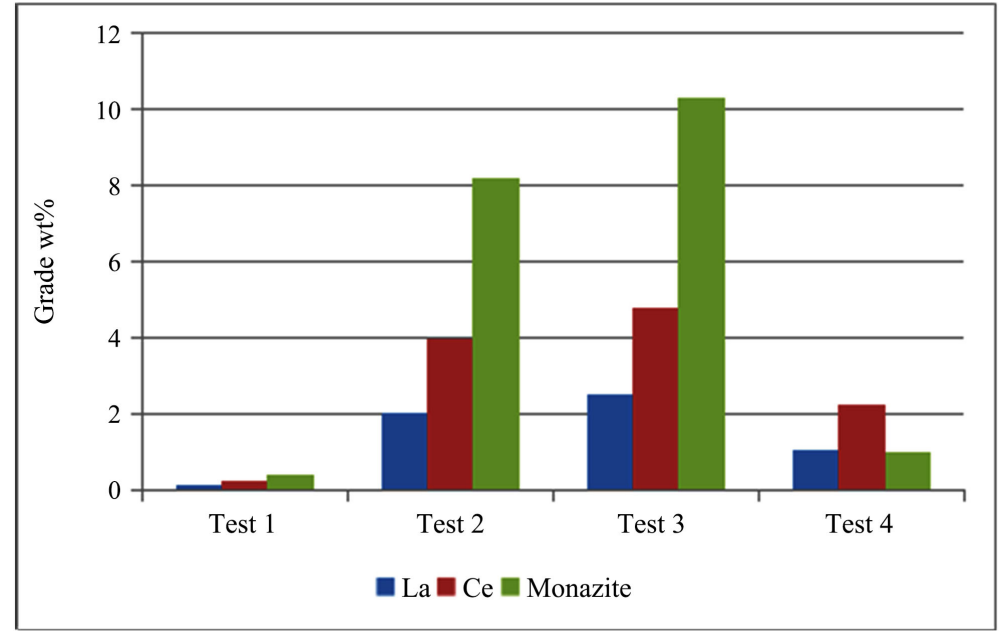

(a)

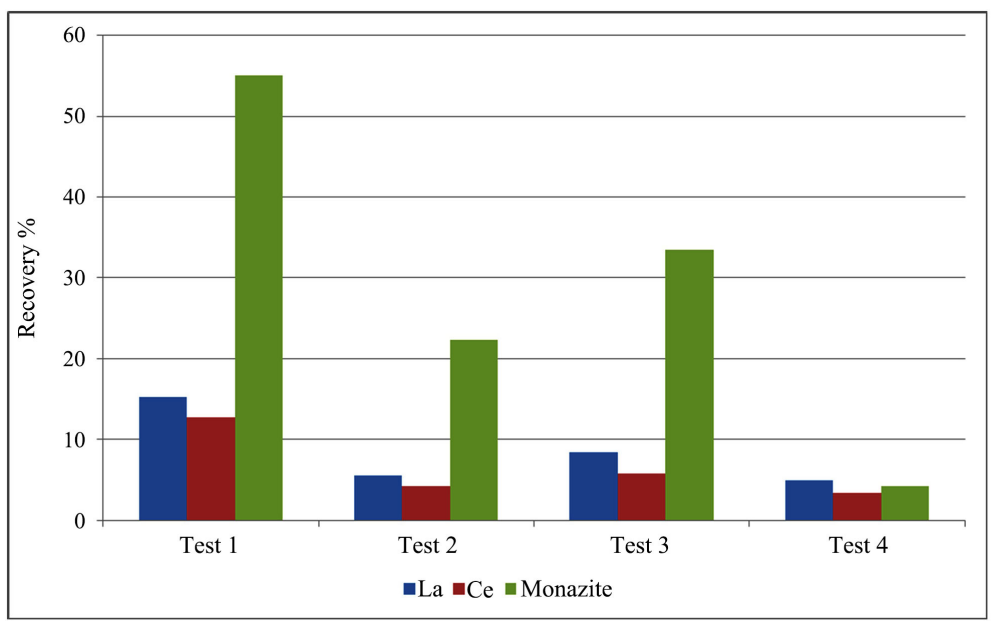

(b)

Figure 1. REEs (Ce and La) and REE-bearing mineral (monazite) grades and recoveries of beneficiation concentrates by physical methods ((a) grade wt\%; (b) recovery \%) (Test 1: PG directly treated by HGMS; Test 2: PG treated by flotation and HGMS; Test 3: PG ground first and treated by flotation and HGMS; Test 4: PG deslimed by hydrodynamic sedimentation and treated by HGMS) [22].

leaching results showed that $80^{\circ} \mathrm{C}, 1.5 \mathrm{~mol} / \mathrm{l}$ concentration, $\mathrm{S} / \mathrm{L}$ of $1 / 8$ and 20 min were the most suitable operating conditions for the three acids.

Ismail et al. (2015) [24] also investigated the leaching of different lanthanides with $\mathrm{HCl}, \mathrm{H}_{2} \mathrm{SO}_{4}$ and $\mathrm{HNO}_{3}$ using the $\mathrm{PG}$ from Abu-Zaabal Company in Egypt. The total content of lanthanides in the PG was found to be about $480 \mathrm{mg} / \mathrm{kg}$. Parameters of acid concentration, mixing time, and acid to PG (L/S) ratio as well as temperature were tested. The highest leaching efficiency was obtained at the conditions of $3.0 \mathrm{~mol} / \mathrm{l} \mathrm{HNO}_{3}, \mathrm{~L} / \mathrm{S} 3.0$, mixing time $3.0 \mathrm{~h}$ and room temperature $\left(25^{\circ} \mathrm{C}\right)$. After three cycles of leaching, the leached out lanthanides from the PG was more than $66 \%$. It was found that the leaching efficiency was different for individual lanthanides and La had the highest leaching efficiency, that is, 73.4\% La, 68.0\% Ce, 62.3\% Er, 55.1\% Y and 39.5\% Pr. 
In addition, the addition of $\mathrm{Ca}\left(\mathrm{NO}_{3}\right)_{2}$ to $\mathrm{HNO}_{3}$ solution was found to increase the leaching efficiency of lanthanides, e.g. as $\mathrm{Ca}\left(\mathrm{NO}_{3}\right)_{2}$ concentration increased from 0.0 to $1.0 \mathrm{~mol} / 1$ in $3.0 \mathrm{~mol} / 1 \mathrm{HNO}_{3}$ solution the leaching efficiency increased from $47.4 \%$ to $59.5 \%$ then it remained almost constant with further increasing $\mathrm{Ca}\left(\mathrm{NO}_{3}\right)_{2}$ concentration up to $2.0 \mathrm{~mol} / \mathrm{l}$. The addition of $\mathrm{NaNO}_{3}$ or $\mathrm{Mg}\left(\mathrm{NO}_{3}\right)_{2}$ in the concentration range from $0.1-2.0 \mathrm{~mol} / \mathrm{l}$ had no effect on leaching efficiency of lanthanides. The study by Preston et al. (1996) [13] also showed that the leaching of the rare earth values from the PG of a South Africa apatite ore by diluted $\mathrm{HNO}_{3}$ was considerably enhanced by the addition of $\mathrm{Ca}\left(\mathrm{NO}_{3}\right)_{2}$ to the lixiviant, enabling recoveries of up to $85 \%$ achieved. The mechanisms could be that the addition of calcium ions lowered the concentration of free fluoride ion (it was observed that the concentration of REEs in the leach liquors might be dependent upon the various fluoride-related equilibria), or the high calcium concentration in solution naturally tended to displace the REEs from the solid phase, in which they were heterovalently substituted for calcium ions [13].

The studies above showed that $\mathrm{HCl}$ and $\mathrm{HNO}_{3}$ were more efficient agencies than $\mathrm{H}_{2} \mathrm{SO}_{4}$ for leaching REEs from $\mathrm{PG}$, but $\mathrm{H}_{2} \mathrm{SO}_{4}$ was still industrially preferred because of economical reasons. A two-step leaching method was introduced with $\mathrm{H}_{2} \mathrm{SO}_{4}$ as the lixiviant using a Tunisian PG [25]. The PG sample was firstly washed with distilled water and after solid-liquid separation underwent a double leaching with $10 \% \mathrm{H}_{2} \mathrm{SO}_{4}$ solution at $60^{\circ} \mathrm{C}$, for $1-2 \mathrm{~h}$ of continuous stirring at L/S ratio of 1.3. After a first lixiviation with the acid solution, the first residue was obtained and was remixed with the same leach liquor for the second lixiviation. Then, after solid-liquid separation, the final filtrate was evaporated at $100^{\circ} \mathrm{C}$ and a solid crystallization was resulted. After washing and filtration a REEs rich solid product was achieved. Analyses by XRD and ICP-MS showed that the impurities such as fluorides and phosphates were essentially dissolved in the first acid leaching, whereas the second leaching led to the dissolution of REEs in the $\mathrm{H}_{2} \mathrm{SO}_{4}$ liquor. The crystallized solid obtained after the evaporation stage corresponded to a mixture of anhydrite $\left(\mathrm{CaSO}_{4}\right)$ and monetite $\left(\mathrm{CaHPO}_{4}\right)$ phases with a total REEs enrichment of about $86 \%$. This study showed that comparing to a single leaching the two-step leaching could improve the leaching efficiency of REEs which allowed a better solubilization of REEs. However, for some PG samples with low concentrations of the impurities such as fluorides and phosphates this process might not profit the leaching efficiency of REEs.

\section{Leaching of REEs by Using Organic Chemicals as the Lixiviants}

Treatment of PG using suitable organic extractants was investigated with a PG sample from Egypt [26]. Different types of organic extractants, such as tributylphosphine (TBP), trioctyl phosphine oxide (TOPO), triphenyl phosphine oxide (TPPO), and di-ethyl-hexyl phosphoric acid (DEHPA), dissolved in kerosene were experimented to investigate the effect of different solvents on the removal 
efficiency of radionuclides and REEs from the PG. Using $0.1 \mathrm{~mol} / \mathrm{l}$ concentration for each solvent, the processes were carried out at room temperature $\left(25^{\circ} \mathrm{C}\right)$; contact time $1 \mathrm{~h}$; and L/S ratio 1.0. The results showed that the highest efficiency (\%) of REEs was obtained by using TBP. By the addition of TBP, $46 \%$ of REEs was removed. The optimized leaching conditions for treating the PG using TBP dissolved in kerosene determined by experiments were: contact time $2 \mathrm{~h}$; concentration of TBP $0.5 \mathrm{~mol} / 1$ (dissolved in kerosene); L/S ratio 1:1 (solution vol./PG wt.); temperature $55^{\circ} \mathrm{C}$ (depending on the vapor pressure of the used solvent). At the conditions the obtained leaching efficiency of REEs reached $68.5 \%$. The method was improved by using mixtures of TBP and TOPO in kerosene. In this case the REE recovery of $80 \%$ was achieved [27].

Leaching of lanthanides from PG using Nonyl Phenol Ethoxylate (NPE) associated with $\mathrm{HNO}_{3}$ and $\mathrm{HCl}$ was conducted by Kouraim et al. (2014) [28] with the PG sample from the processing of Abu-Tartur phosphate ores in Egypt. The content of total lanthanides in the PG was $1387 \mathrm{mg} / \mathrm{kg}$ and highly concentrated in the fine size fraction $(<20 \mu \mathrm{m})$. Leaching of lanthanides was carried out using either free acids $\mathrm{HCl}$ and $\mathrm{HNO}_{3}$ or these acids associated with Nonyl Phenol Ethoxylate (NPE). Based on the experimental results relative to the corresponding free acids the leaching efficiency of lanthanides was increased by $30 \%$ using even small concentrations of NPE $(>4 \mathrm{wt} / \mathrm{v} \%)$ at temperature $25^{\circ} \mathrm{C}$. The factors affecting the leaching process were optimized. The kinetics of the leaching process was investigated as a function of temperature. It was found that the leaching process could be described by a shrinking-core model and in the leaching of lanthanides by the associated system the activation energy was decreased from $5.89 \mathrm{~kJ} / \mathrm{mol}$ to $5.28 \mathrm{~kJ} / \mathrm{mol}$ and $12.24 \mathrm{~kJ} / \mathrm{mol}$ to $3.79 \mathrm{~kJ} / \mathrm{mol}$ for $\mathrm{HCl}$ and $\mathrm{HNO}_{3}$, respectively.

\section{Influences of Mechanical Activations on Leaching of REEs}

The effect of microwaving PG as the pre-treatment on acid leaching was investigated [29]. It was found that microwave radiation resulted in the dielectric heating of water molecules in the crystals and vaporization, causing the formation of breaks and pores in these particles as the vapour escaped.

An extraction method of REEs from a Russian PG was presented by processing the PG with sulfuric acid $(0.3-0.6 \mathrm{~mol} / \mathrm{l})$ at high temperatures of $70^{\circ} \mathrm{C}-100^{\circ} \mathrm{C}$ and S:L ratio of 1:1-3 for $1-2 \mathrm{~h}$ under stirring and bubbling of air into the pulp [30]. But the leaching efficiency was not revealed.

The influences of mechanoactivation by grinding on the overall solubility of $\mathrm{CaSO}_{4} \cdot 2 \mathrm{H}_{2} \mathrm{O}$ and of $\mathrm{PG}$ in water and in diluted acids $\left(10 \% \mathrm{HCl}, 7 \% \mathrm{H}_{2} \mathrm{SO}_{4}\right)$ as well as on the leaching efficiency of REEs from the PG were studied [31]. The PG sample was from Kola apatite processing. The content of REEs was 3700 $\mathrm{mg} / \mathrm{kg}$ including $\mathrm{La}, \mathrm{Ce}, \mathrm{Pr}$, and $\mathrm{Nd}$. The grinding was performed in a centrifugal ball mill in air and in suspension with the acids. The results showed that the leaching of REEs from the PG was improved by the mechanoactivation in air, water and acids. 
REEs recovery from a PG by leaching using a patented leaching solution (PX-107) followed by REEs extraction with a polymer (Chelok ${ }^{\circledast}$ ) was reported [32]. The PG sample was milled using a rod mill for 10 minutes and the extraction rates of REEs were compared to those of the unmilled sample as shown in Table 1. It is clear that after the PG sample being milled the extracted REEs was increased for almost all the REEs.

The influence of mechanoactivation by grinding was investigated with a PG material from a mine in Europe [33]. The material was ground using a ball mill for 30, 60 and $90 \mathrm{~min}$ and acid leaching experiments were conducted with $\mathrm{HCl}$ and $\mathrm{HNO}_{3}$. The leached rates of REEs including $\mathrm{La}, \mathrm{Ce}$ and $\mathrm{Y}$ for unmilled and milled samples (at grinding time of 30, 60 and $90 \mathrm{~min}$ ) were compared in Table 2 and Table 3. It is seen the leaching efficiencies of REEs, La, Ce and Y, were improved by milling and also generally the leached rates increased as the milling time increasing.

Table 1. Comparison of extraction efficiencies of REEs for the unmilled and milled samples [32].

\begin{tabular}{ccccccc}
\hline $\begin{array}{c}\text { Extraction rate of } \\
\text { REEs } \%\end{array}$ & Ce & Dy & Er & Gd & Ho & La \\
\hline Unmilled & 47.72 & 74.46 & 79.92 & 59.54 & 39.20 & 72.65 \\
Milled & 49.54 & 85.25 & 89.89 & 68.12 & 58.87 & 87.37 \\
$\begin{array}{c}\text { Extraction rate of } \\
\text { REEs \% }\end{array}$ & $\mathrm{Nd}$ & $\mathrm{Sm}$ & $\mathrm{Tb}$ & $\mathrm{Y}$ & $\mathrm{Yb}$ & $\mathrm{Pr}$ \\
Unmiled & 85.25 & 77.33 & 49.71 & 61.80 & 73.08 & 10.69 \\
Milled & 99.11 & 84.94 & 88.49 & 69.70 & 80.36 & 4.57 \\
\hline
\end{tabular}

Table 2. Comparison of REE leached rates for unmilled and milled samples $(\mathrm{HCl}, 4.0$ $\mathrm{mol} / \mathrm{l}, 60^{\circ} \mathrm{C}, 120 \mathrm{~min}$ ) [33].

\begin{tabular}{|c|c|c|c|c|}
\hline \multicolumn{2}{|c|}{$\begin{array}{l}\text { Extraction rate of } \\
\text { REEs \% }\end{array}$} & $\mathrm{La}$ & $\mathrm{Ce}$ & $\mathrm{Y}$ \\
\hline \multicolumn{2}{|c|}{ Unmilled } & 51.80 & 54.76 & 46.11 \\
\hline \multirow{3}{*}{ Milled } & $30 \mathrm{~min}$ & 64.47 & 60.48 & 70.79 \\
\hline & $60 \mathrm{~min}$ & 59.83 & 61.35 & 68.12 \\
\hline & $90 \mathrm{~min}$ & 72.21 & 62.86 & 84.56 \\
\hline
\end{tabular}

Table 3. Comparison of REE leached rates for unmilled and milled samples $\left(\mathrm{HNO}_{3}, 4.0\right.$ $\mathrm{mol} / \mathrm{l}, 60^{\circ} \mathrm{C}, 120 \mathrm{~min}$ ) [33].

\begin{tabular}{|c|c|c|c|c|}
\hline \multicolumn{2}{|c|}{$\begin{array}{l}\text { Extraction rate of } \\
\text { REEs \% }\end{array}$} & $\mathrm{La}$ & $\mathrm{Ce}$ & $\mathrm{Y}$ \\
\hline \multicolumn{2}{|c|}{ Unmilled } & 59.92 & 57.93 & 54.61 \\
\hline \multirow{3}{*}{ Milled } & $30 \mathrm{~min}$ & 61.69 & 66.91 & 83.74 \\
\hline & $60 \mathrm{~min}$ & 75.43 & 70.32 & 88.30 \\
\hline & $90 \mathrm{~min}$ & 70.52 & 73.04 & 79.31 \\
\hline
\end{tabular}


The improvement of mechanoactivation by grinding on leaching efficiency of REEs could be attributed to the increase of the specific area and the decrease of the visual activation energy of ground material because of crystal interior defects [34].

\section{Resin-in-Leach}

The study by Koopman and Witkamp (2000) [8] showed that during the wetprocess of phosphoric acid production using sulfuric acid to the apatite concentrate the calcium sulfate hemihydrate $(\mathrm{HH})$ was formed first, then recrystallized into calcium sulfate dihydrate $(\mathrm{DH})$ or gypsum. REEs were incorporated to gypsum during the recrystallization. The extraction efficiency of lanthanides on the DOWEX C-500 resin (a strongly acidic cation exchange resin with $4.9 \mathrm{meg} / \mathrm{g}$ of sulfonic acid functional groups and a size of $465-635 \mu \mathrm{m}$ ) during the recrystallization of hemihydrate $(\mathrm{HH})$ to gypsum was investigated. The experiments were carried out in the system of phosphoric acid, gypsum seeds, $\mathrm{HH}$, and DOWEX C-500 resin at the temperature of $80^{\circ} \mathrm{C}$. The results showed that with $250 \mathrm{~g}$ resin/kg phosphoric acid, lanthanides can be removed during the recrystallization of $\mathrm{HH}$ to gypsum. Depending on the value of the distribution coefficient $\mathrm{K}_{\mathrm{A}, \mathrm{DH}}^{\prime}$ for each element, the removal percentages were $53 \%$ for $\mathrm{Eu}, 34 \%$ for $\mathrm{La}$ and $10 \%$ for $\mathrm{Sm}$. Meanwhile, the results showed that the ion exchange resin also extracted bivalent calcium ions $\left(\mathrm{Ca}^{2+}\right)$ which could be selectively precipitated from concentrated hydrochloric or nitric acid solutions.

The resin-in-leach technology for extraction of REEs was studied by processing a PG material using sulphuric acid as the lixiviant in South Africa [35]. The process parameters including types of resin, unprocessed and processed PG by hydro-cycloning, with and without additives etc. were tested. The adsorbed REEs on the resins were eluted by using $\mathrm{CaCl}$. The results indicated that resin-in-leach process was feasible for recovery of REEs from PG.

\section{Conclusions}

The occurrence phases of REEs in the PG were concerned in many studies but conclusions were disputable. According to these studies REEs occur as minerals and also being adsorbed as $\mathrm{REEs}^{3+}$ ions. In a recently published study it was shown that gypsum as the dominating mineral in the PG was detected to be the major REE-bearing phase carrying over $72 \%$ of REEs in the material.

In a case study, physical beneficiation of PG by flotation and magnetic separation methods was investigated and the results showed that the REE-bearing minerals in the PG such as monazite could be enriched by physical methods but REEs such as La and Ce were not concentrated with high recoveries because gypsum, as a major REEs-bearing phase, carrying most of REEs in the PG, was not able to be efficiently enriched by physical methods.

Studies on acid leaching with $\mathrm{H}_{2} \mathrm{SO}_{4}, \mathrm{HCl}$ and $\mathrm{HNO}_{3}$ were conducted. Acid concentration, temperature, solid to liquid ratio, operation time and the addition 
of $\mathrm{Ca}\left(\mathrm{NO}_{3}\right)_{2}$ to $\mathrm{HNO}_{3}$ solution were found by experiments to be effective parameters for REEs leaching from PG. $\mathrm{HCl}$ and $\mathrm{HNO}_{3}$ were found to be more efficient solvents than $\mathrm{H}_{2} \mathrm{SO}_{4}$ for leaching REEs from PG. $\mathrm{H}_{2} \mathrm{SO}_{4}$ might be still industrially preferred because of economical reasons. A study showed that two-step leaching using $\mathrm{H}_{2} \mathrm{SO}_{4}$ could improve the leaching efficiency of REEs for a PG material.

Some organic chemicals such as tributylphosphine (TBP) and trioctyl phosphine oxide (TOPO), or their mixture, dissolved in kerosene were proved by experiments to be effective lixiviants for leaching REEs from PG.

Influences of mechanical activations by grinding were found to be significant on leaching of REEs from PG. The activation mechanisms may need to be further studied for economical use of this process.

Resin-in-leach process using sulphuric acid as the lixiviant would be feasible for recovery of REEs from PG. The selectivity of the ion exchange resins to REEs ions and bivalent calcium ions could be the most important factor affecting practical use of the process.

\section{Acknowledgements}

The authors are grateful to the Academy of Finland (298094) for the financial support.

\section{Conflicts of Interest}

The authors declare no conflicts of interest regarding the publication of this paper.

\section{References}

[1] Zhang, P. (2014) Comprehensive Recovery and Sustainable Development of Phosphate Resources. Procedia Engineering, 83, 37-51. https://doi.org/10.1016/j.proeng.2014.09.010

[2] Rutherford, P.M., Dudas, M.J. and Samek, R.A. (1994) Environmental Impacts of Phosphogypsum. Science of the Total Environment, 149, 1-38.

https://doi.org/10.1016/0048-9697(94)90002-7

[3] Binnemans, K., Jonesb, P.T., Blanpainb, B., Gervenc, T.V. and Pontikesbet, Y. (2015) Towards Zero-Waste Valorisation of Rare-Earth-Containing Industrial Process Residues: A Critical Review. Journal of Cleaner Production, 99, 17-38. https://doi.org/10.1016/j.jclepro.2015.02.089

[4] Grabas, K., Pawelczyk, A., Stręk, W., Szelęg, E. and Stręk, S. (2018) Study on the Properties of Waste Apatite Phosphogypsum as a Raw Material of Prospective Applications. Waste and Biomass Valorization, 1-13. https://doi.org/10.1007/s12649-018-0316-8

[5] Ogawa, Y. and Shikazono, N. (2006) REE Behavior during Anhydrite and Gypsum Formations of the Kuroko Type Massive Sulfide-Sulfate Deposits. In: 3rd International Workshop on Water Dynamics, American Institute of Physics, College Park, 162-166. https://doi.org/10.1063/1.2207096

[6] Ogawa, Y., Shikazono, N., Ishiyama, D., Sato, H., Mizuta, T. and Nakano, T. (2007) 
Mechanisms for Anhydrite and Gypsum Formation in the Kuroko Massive Sulfidesulfate Deposits, North Japan. Mineralium Deposita, 42, 219-233. https://doi.org/10.1007/s00126-006-0101-7

[7] Wang, L.S., Long, Z.Q., Huang, X.W., Yu, Y., Cui, D.L. and Zhang, G.C. (2010) Recovery of Rare Earths from Wet-Process Phosphoric Acid. Hydrometallurgy, 101, 41-47. https://doi.org/10.1016/j.hydromet.2009.11.017

[8] Koopman, C. and Witkamp, G.J. (2000) Extraction of Lanthanides from the Phosphoric Acid Production Process to Gain a Purified Gypsum and a Valuable Lanthanide By-Product. Hydrometallurgy, 58, 51-60.

https://doi.org/10.1016/S0304-386X(00)00127-4

[9] Dutrizac, J.E. (2017) The Behaviour of the Rare Earth Elements during Gypsum $\left(\mathrm{CaSO}_{4} \cdot 2 \mathrm{H}_{2} \mathrm{O}\right)$ Precipitation. Hydrometallurgy, 174, 38-46.

https://doi.org/10.1016/j.hydromet.2017.09.013

[10] Harbi, H.M., Eldougdoug, A.A. and El-Shahwai, M.S. (2011) Mineral Processing and Extraction of Rare Earth Elements from the Wadi Khamal Nelsonite Ore, Northwestern Saudi Arabia. Arabian Journal of Geosciences, 4, 353-363.

https://doi.org/10.1007/s12517-009-0061-1

[11] Sandström, A. and Fredriksson, A. (2012) Apatite for Extraction: Leaching of Kiirunavaara Apatite for Simultaneous Production of Fertilizers and REE. IMPC-2012 Proceedings, Vol. 379, 4707-4714.

[12] Abdelhadi, M., Abdelhadi, N. and El-Hasanet, T. (2018) Optimization of Phosphogypsum By-Production Using Orthophosphoric Acid as Leaching Solvent with Different Temperatures and Leaching Time Periods. Earth Science Research, 7, 28-41. https://doi.org/10.5539/esr.v7n2p28

[13] Preston, J.S., Cole, P.M., Craig, W.M. and Feather, A.M. (1996) The Recovery of Rare Earth Oxides from a Phosphoric Acid By-Product. Part 1 Leaching of Rare Earth Values and Recovery of a Mixed Rare Earth Oxide by Solvent Extraction. $H y$ drometallurgy, 41, 1-19. https://doi.org/10.1016/0304-386X(95)00051-H

[14] Jarosiński, A., Kowalczyk, J. and Mazanek, Cz. (1993) Development of the Polish Wasteless Technology of Apatite Phosphogypsum Utilization with Recovery of Rare Earths. Journal of Alloys and Compounds, 200,147-150. https://doi.org/10.1016/0925-8388(93)90485-6

[15] Jin, H.X., Li, J.Q. and Wu, F.Z. (2011) Acidolysis Kinetics and RE Leaching Mechanics of RE Bearing Phosphorite Ores. Journal of University of Science and Technology Beijing, 33, 1071-1078.

[16] Santos, A.J.G., Mazzilli, B.P., Fávaro, D.I.T. and Sliva, P.S.C. (2006) Partitioning of Radionuclides and Trace Elements in Phosphogypsum and Its Source Materials Based on Sequential Extraction Methods. Journal of Environmental Radioactivity, 87, 52-61. https://doi.org/10.1016/j.jenvrad.2005.10.008

[17] Borges, R.C., Fávaro, D.I.T., Caldas, V.G., Lauria, D.C. and Bernedo, A.V.B. (2016) Instrumental Neutron Activation Analysis, Gamma Spectrometry and Geographic Information System Techniques in the Determination and Mapping of Rare Earth Element in Phosphogypsum Stacks. Environmental Earth Sciences, 75, 1-15. https://doi.org/10.1007/s12665-016-5468-x

[18] Schmidt, M., Stumpf, T., Walther, C., Geckeis, H. and Franghänel, T. (2009) Incorporation versus Adsorption: Substitution of $\mathrm{Ca}^{2+}$ by $\mathrm{Eu}^{3+}$ and $\mathrm{Cm}^{3+}$ in Aragonite and Gypsum. Dalton Transactions, 7, 6645-6650. https://doi.org/10.1039/b822656c

[19] Walawalkar, M., Nichol, C.K. and Gisele Azimi, G. (2016) Process Investigation of the Acid Leaching of Rare Earth Elements from Phosphogypsum Using $\mathrm{HCl}, \mathrm{HNO}_{3}$, 
and $\mathrm{H}_{2} \mathrm{SO}_{4}$. Hydrometallurgy, 166, 195-204.

https://doi.org/10.1016/j.hydromet.2016.06.008

[20] Alhassanieh, O., Mrad, O. and Ajji, Z. (2012) Sorption and Migration of Cs, Sr, and Eu in Gypsum-Groundwater System. Nukleonika, 57, 125-131.

[21] Yang, X., Makkonen, H.T. and Pakkanen, L. (2019) Rare Earth Occurrences in Streams of Processing a Phosphate Ore. Minerals, 9, 262. https://doi.org/10.3390/min9050262

[22] Yang, J. (2017) Reprocessing of Phosphogypsum for Recovery of REE. Prometia Scientific Seminar, Barcelona, 28-29 November 2017.

[23] Azimi, G., Papangelakis, V.G. and Dutrizac, J.E. (2008) Development of an MSE-Based Chemical Model for the Solubility of Calcium Sulphate in Mixed Chloride-Sulphate Solutions. Fluid Phase Equilibria, 266, 172-186. https://doi.org/10.1016/j.fluid.2008.01.027

[24] Ismail, Z.H., Abu Elgoud, E.M., Abdel Hai, F., Ali, I.O., Gasser, M.S. and Aly, H.F. (2015) Leaching of Some Lanthanides from Phosphogypsum Fertilizers by Mineral Acids. Arab Journal of Nuclear Science and Applications, 48, 37-50.

[25] Hammas-Nasri, I., Horchani-Naifer, K., Férid, M. and Barca, D. (2016) Rare Earths Concentration from Phosphogypsum Waste by Two-Step Leaching Method. International Journal of Mineral Processing, 149, 78-83.

https://doi.org/10.1016/j.minpro.2016.02.011

[26] El-Didamony, H., Ali, M.M., Awwad, N.S., Fawzy, M.M. and Attallah, M.F. (2012) Treatment of Phosphogypsum Waste Using Suitable Organic Extractants. Journal of Radioanalytical and Nuclear Chemistry, 291, 907-914.

https://doi.org/10.1007/s10967-011-1547-3

[27] EI-Didamony, H., Gado, H.S., Awwad, N.S., Fawzy, M.M. and Attallah, M.F. (2013) Treatment of Phosphogypsum Waste Produced from Phosphate Ore Processing. Journal of Hazardous Materials, 244, 596-602. https://doi.org/10.1016/j.jhazmat.2012.10.053

[28] Kouraim, M.N., Fawzy, M.M. and Helaly, O.S. (2014) Leaching of Lanthanides from Phosphogypsum Waste Using Nonyl Phenol Ethoxylate Associated with $\mathrm{HNO}_{3}$ and $\mathrm{HCl}$. International Journal of Sciences. Basic and Applied Research, 16, 31-44.

[29] Reid, S., Walawalkari, M. and Azimi, G. (2017) Valorization of Rare Earth-Containing Landfilled Stocks of Industrial Process Residues: Phosphogypsum and Red Mud. ERES 2017, Santorini, 28-31 May 2017, 164-165.

[30] Valkov, A.V., Andreev, V.A., Anufrieva, A.V., Makaseev, Y.N., Bezrukova, S.A. and Demyanenko, N.V. (2014) Phosphogypsum Technology with the Extraction of Valuable Components. Procedia Chemistry, 11, 176-181. https://doi.org/10.1016/j.proche.2014.11.031

[31] Todorovsky, D., Terziev, A. and Milanova, M. (1997) Influence of Mechanoactivation on Rare Earths Leaching from Phosphogypsum. Hydrometallurgy, 45, 13-19. https://doi.org/10.1016/S0304-386X(96)00065-5

[32] Laurino, J.P. and Mustacato, J. (2015) The Extraction and Recovery of Rare Earth Elements from Phosphate Using PX-107 and CHELOK ${ }^{\oplus}$ Polymers (Report). The Florida Industrial and Phosphate Research Institute, Publication No. 02-189-255.

[33] Yang, X. (2019) REE-PG Project Report.

[34] Li, H. (1998) Chapter 2 Leaching, Science of Hydro-Metallurgy. Central South University Press, Changsha. (In Chinese) 
[35] Padayachee, A.M.A., Johns, M.W. and Green, B.R. (1996) The Use of Ion Exchange Resins to Recover Rare Earths from Apatite Gypsum Residue. In: Greig, J.A., Ed., Ion Exchange Developments and Applications, The Royal Society of Chemistry, London, 380-387. 